Regina Heloisa Maciel ${ }^{1}$

Rosemary Cavalcante Gonçalves ${ }^{1}$

Tereza Glaucia Rocha Matos ${ }^{1}$

Marselle Fernandes Fontenelle ${ }^{2}$

João Bosco Feitosa dos Santos ${ }^{3}$
${ }^{1}$ Universidade de Fortaleza, Programa de Pós-graduação em Psicologia. Fortaleza, CE, Brasil.

${ }^{2}$ Universidade de Fortaleza, Departamento de Psicologia. Fortaleza, CE, Brasil.

${ }^{3}$ Universidade Estadual do Ceará, Programa de Pós-graduação em Políticas Públicas e Sociedade. Fortaleza, CE, Brasil.

Contato:

Regina Heloisa Maciel

E-mail:

reginaheloisamaciel@gmail.com

O trabalho não foi baseado em dissertação de mestrado ou tese de doutorado e não foi apresentado em reuniões científicas.

Apoio: Projeto de pesquisa financiado por FUNCAP/CNPq/PPSUS-MS/SESA, Projeto n. 09100046-7.

Os autores declaram não haver conflitos de interesses.

\section{Análise da dinâmica do trabalho portuário: estudo comparativo entre os portos do Mucuripe e do Pecém, no Ceará}

\author{
Analysis of dock work dynamics: a comparative study between \\ the ports of Pecém and Mucuripe in Ceará
}

\begin{abstract}
Resumo
Introdução: apresenta-se uma análise do trabalho nos dois portos do Estado do Ceará - o Porto do Mucuripe, que, pela Lei de Modernização dos Portos de 1993, possui um Órgão Gestor de Mão de Obra responsável pela gestão dos Trabalhadores Portuários Avulsos, e o Porto do Pecém, terminal de uso privado misto, administrado por empresa pública, que funciona com prestadora de serviços. Objetivos: comparar os portos quanto às condições de trabalho e à dinâmica laboral de operações específicas comuns aos dois portos, assim como os riscos à saúde dos trabalhadores envolvidos nas atividades operacionais. Métodos: entrevistas com gerentes, técnicos e trabalhadores, bem como observações e filmagens das operações portuárias nos anos de 2010 e 2011. Resultados: o trabalho em ambos os portos assemelha-se quanto a operações, maquinário e na exposição a riscos. A análise mostrou diferenças no tipo de carga manuseada nos dois portos e em algumas das atividades desenvolvidas, mas constatou-se que a principal diferença se dá na organização do trabalho. As diferenças residem na forma de contratação e remuneração, supervisão e ritmo de trabalho. Conclusões: as inovações tecnológicas, como informaram os entrevistados, levaram à redução de alguns agravos à saúde nos dois portos, mas a reestruturação produtiva, concretizada na lei, trouxe novos riscos ocupacionais e possibilitou a intensificação do ritmo de trabalho.
\end{abstract}

Palavras-chave: trabalhadores portuários; modernização portuária; saúde do trabalhador.

\begin{abstract}
Introduction: this paper presents a dock work analysis of two ports localized in state of Ceará - Mucuripe which, after the implementation of the Brazilian Ports Modernization Act of 1993, has a Workmanship Management Agency, responsible for dockworkers management, and Pecém, which is a mixed private terminal, managed by a State-owned company that works through service providers. Objectives: to compare the work conditions and the labor dynamics of specific operations common to both ports, as well as the risks to the health of the workers involved in these operations. Methods: interviews with managers, technicians and workers, as well as observation and video recordings of dock operations taken during 2010 and 2011. Results: work on both ports resembles in operations, machinery and risk exposure. There were differences between the two ports on the type of load handled and in some operations. However, the main differences reside in the manner in which workers are hired and paid, in the supervision and work pace. Conclusions: as stated by the subjects interviewed, due to technological innovations, some risks have been reduced in the two ports, but productive restructuring has brought new occupational hazards and made the intensification of work possible.
\end{abstract}

Keywords: dockworkers; dock modernization; workers' health. 


\section{Introdução}

As transformações que ocorreram desde o final dos anos de 1980 levaram o Brasil a reformular o seu sistema portuário com o objetivo de melhorar sua eficiência produtiva e assim adequar os portos brasileiros ao aumento das transações portuárias decorrentes da intensificação do comércio internacional. A globalização econômica, da qual derivam essas transformações, tem como ponto principal um aumento no fluxo de mercadorias transportadas por navios de um continente a outro, de costa a costa, o qual tornou o transporte marítimo, uma atividade meio, atividade econômica altamente lucrativa (MARCHETTI; PASTORI, 2006).

As mudanças ocorridas nos portos brasileiros nas últimas décadas não são uma experiência inédita. Nos últimos 25 anos, os portos de quase todos os países do mundo foram objeto de reformas extensas com o fim de adaptá-los à nova ordem econômica no cenário político internacional (PÉREZ, 2008; TONGZON; HENG, 2005; BROOKS, 2004; SAUNDRY; TURNBULL, 1999).

No Brasil, até 2013, a Lei n. 8.630/93 - Lei de Modernização dos Portos (BRASIL, 1993) - foi o único documento norteador de todas as mudanças do sistema portuário brasileiro (MONIÉ; VIDAL, 2006). Nesse ano se deu a publicação da Nova Lei dos Portos (BRASIL, 2013a) e do Decreto n. 8.033 (BRASIL, 2013b). Esses marcos legais não somente fizeram ajustes no setor portuário, mas trouxeram uma profunda reestruturação no cotidiano das práticas portuárias brasileiras, apostando na iniciativa privada como forma de solucionar os problemas do setor (GOULARTI FILHO, 2007). Dentre as principais transformações, pode-se citar que o Estado continua a ser responsável pela administração e investimento na infraestrutura portuária, mas que a operação do porto é cedida à iniciativa privada, inclusive a compra de equipamentos e a contratação de mão de obra (ARAÚJO, 2013). Por outro lado, a nova legislação concede ainda a possibilidade de criação e exploração de portos privados.

A reestruturação produtiva imposta pela legislação levou a um extenso processo de privatizações e de investimentos em novas tecnologias portuárias, trazendo para o cenário dos portos novos atores denominados operadoras e prestadoras (empresas que realizam a logística do trabalho portuário) e Órgão Gestor de Mão de Obra (OGMO), no caso dos Portos Organizados (portos com administração pública), que agencia a mão de obra dos Trabalhadores Portuários Avulsos (TPA).

No que se refere aos terminais privados, as operadoras e prestadoras realizaram altos investimentos em equipamentos destinados à movimentação de mercadorias e adotaram um novo modelo de gestão a fim de elevar a qualidade dos serviços e reduzir os custos, principalmente da mão de obra. A lógica empregada é a de que quanto maior a movimentação de cargas, através do uso de máquinas, e menor a quantidade de trabalho humano, mais barato fica o serviço (TORRES, 2008). As mudanças ocasionaram uma redução dos postos de trabalho, a inclusão e extinção de funções, a introdução do trabalhador multifuncional, o aumento da jornada e do ritmo de trabalho, assim como o estabelecimento de patamares superiores de produtividade, exigidos pelos compradores dos serviços. Gomes e Junqueira (2008) acreditam que a ação adotada pela força modernizadora supervaloriza a razão técnica, deixando de lado a questão dos trabalhadores e sua exposição aos riscos inerentes ao trabalho.

A modernização portuária tem significado para os trabalhadores a perda da autonomia, com o aniquilamento da capacidade de gerirem, através dos sindicatos, como faziam antes, a mão de obra e os interesses da categoria. As mudanças afetaram os valores da tradição e o significado de pertencimento que faziam sentido com a união sindical (NASCIMENTO, 1999). Antes da modernização, os trabalhadores eram marcados por relações de parentesco ou amizade e o exercício do trabalho dependia mais de informações personalizadas, de favores, ou, ainda, da condição política (sindicato), do que da resposta dada pelo mercado ou por empresas especializadas na contratação de mão de obra (MACHIN; COUTO; ROSSI, 2009).

As atividades portuárias nos Portos Organizados são realizadas por trabalhadores avulsos que, por definição, prestam serviços a várias empresas, agrupados em entidades de classe, contratados por intermédio dessas e sem vínculo empregatício. Caracterizam o trabalho avulso a intermediação do sindicato ou órgão específico de colocação de mão de obra, a curta duração dos serviços e a prevalência da forma de rateio para a remuneração (CARRION, 2003). No caso dos Terminais de Uso Privado (TUPs), as prestadoras gerem a mão de obra da forma mais conveniente, não há órgão gestor e independentemente dos sindicatos.

O trabalho nos portos varia de acordo com a mercadoria a ser transportada ou manuseada, seu acondicionamento e o transporte requerido. $\mathrm{O}$ trabalho é diversificado e definido como nobre e não nobre. No primeiro caso, utiliza-se maquinaria; no segundo, depende-se exclusivamente do esforço físico. O tipo de carga define a remuneração (AGUIAR; JUNQUEIRA; FREDDO, 2006).

As funções e atividades dos trabalhadores portuários, dependendo da região e do porto, apresentam pequenas diferenças nas definições das tarefas desenvolvidas. Magioli (2008) classifica funções e respectivas atividades conforme apresentado no Quadro 1. 
Quadro 1 Funções e atividades desenvolvidas pelos trabalhadores portuários*

\begin{tabular}{|c|l|}
\hline Função & \multicolumn{1}{|c|}{ Atividades desenvolvidas } \\
\hline Capataz & $\begin{array}{l}\text { Supervisiona a movimentação de mercadorias: Recebimento, conferências, transporte } \\
\text { interno, abertura de volumes para a conferência, manipulação, arrumação, entrega da } \\
\text { carga, carregamento e descarregamento de embarcações com uso de aparelhamento em } \\
\text { terra e a bordo. }\end{array}$ \\
\hline Guindasteiro & $\begin{array}{l}\text { Movimenta contêineres ou carga da carreta para o navio e vice-versa por meio de } \\
\text { guindaste ou portêiner. }\end{array}$ \\
\hline Portuário & Movimenta cargas em terra. \\
\hline Estivador & $\begin{array}{l}\text { Movimenta todo tipo de equipamento ou carga dentro dos navios. Estivagem e } \\
\text { desestivagem: Arrumação e retirada das mercadorias exclusivamente no convés e nos } \\
\text { porões do navio. }\end{array}$ \\
\hline Vigilante & Vigia para que não entrem no navio pessoas não autorizadas. \\
\hline Sinaleiro & $\begin{array}{l}\text { Sinaliza para começar e terminar as operações. Essa atividade é realizada pelos } \\
\text { chamados portuários. }\end{array}$ \\
\hline Conferente & Confere as taras*** em terra conforme o especificado nas notas fiscais. \\
\hline
\end{tabular}

*Baseado em Magioli (2008).

栐Tara: Peso que se abate do peso bruto de uma mercadoria, equivalente ao do recipiente, carro, caixa ou invólucro em que ela se acha ou é transportada (TARA, 2009).

As condições de trabalho e a gerência dos riscos do trabalho portuário são estabelecidas pela Norma Regulamentadora 29 - NR29 (BRASIL, 1997). A Norma Regulamentadora (NR) define diretrizes de segurança e saúde referentes aos trabalhadores que exercem atividades no contexto portuário e apresenta medidas obrigatórias com o intuito de prevenir acidentes e doenças do trabalho. No entanto, como ocorre com a maioria das demais NRs, as condições mínimas não garantem ambientes de trabalho totalmente livres de risco e nem sempre as instâncias de fiscalização e controle funcionam adequadamente. Além disso, as NRs, seguidoras das abordagens tradicionais da medicina e segurança do trabalho, em muitos casos não alcançam a complexidade da multicausalidade dos acidentes e doenças ocupacionais (LACAZ, 2007; PORTO, 2000).

O ambiente de trabalho portuário, em geral, apresenta riscos à saúde e à vida dos trabalhadores que efetuam essas atividades em contextos diversos, de acordo com a demanda dos serviços. Os riscos do trabalho portuário estão relacionados não apenas às condições físicas do trabalho (presença de ruídos e vibrações de máquinas, exposição a intempérie e temperaturas extremas, exposição a substâncias químicas, levantamento manual de carga, uso de ferramentas de trabalho inadequadas, condições físicas inadequadas do terminal portuário, queda de objetos suspensos, trabalho em altura, tráfego de máquinas, entre outros) mas também a condições organizacionais e psicossociais (falta de orientação e supervisão dos trabalhadores quanto à saúde, composição das equipes de trabalho em número abaixo do ideal, ganho por produtividade e ritmo de trabalho elevado) (SOARES et al., 2008; SOARES; CEZAR-VAZ; SANT'ANNA, 2011).
Cavalcanti et al. (2005), estudando os estivadores do Porto do Mucuripe, encontraram como principais problemas de saúde desses trabalhadores os distúrbios osteoarticulares (hérnia de disco e desgastes na articulação do joelho) e metabólicos (diabetes e hipertensão arterial). No entanto, a pesquisa não realizou uma análise das atividades dos portuários.

Os riscos e acidentes de trabalho no contexto portuário parecem ter se intensificado com as mudanças advindas da nova legislação. Bourguignon e Borges (2006), analisando as Comunicações de Acidentes de Trabalho (CAT) arquivadas no sindicato dos trabalhadores portuários do Espírito Santo, encontraram um aumento no coeficiente de acidentes de trabalho após a implantação das mudanças relacionadas à modernização portuária.

Por outro lado, relatos oficiais referentes à segurança nas operações portuárias quase que invariavelmente culpam os trabalhadores pelos acidentes ocorridos. Lu e Shang (2005), em estudo que revisou relatórios sobre acidentes portuários, evidenciaram que, em mais de $50 \%$ dos relatórios sobre eventos ocorridos em vários portos do mundo, os acidentes são atribuídos aos trabalhadores e não às condições de trabalho.

A partir de uma análise ampliada, considerando elementos pertinentes à modernização portuária, Fabiano et al. (2010) estudaram os acidentes de trabalho ocorridos no Porto de Genova (Itália), entre os anos de 1980 a 2006, tomando o cuidado de não se basearem exclusivamente em relatos oficiais, e concluíram que o aumento da utilização de contêineres e a consequente mudança na infraestrutura portuária para as atividades de embarque e desembarque desses volumes trouxeram modificações no número e característica da força de 
trabalho, com uma diminuição de quase cinco vezes na quantidade de trabalhadores e um aumento de $28 \%$ para $74 \%$ dos que não têm experiência. O aumento significativo de jovens sem experiência nas operações portuárias de manuseio de contêineres e das novas tarefas relacionadas a esse manuseio levou a um aumento dos agravos à saúde relacionados ao trabalho. No porto estudado houve um aumento no risco de acidentes de 13,0 para 29,7 (acidentes por $100 \mathrm{mil}$ horas trabalhadas).

O Ceará possui dois portos que atendem toda a sua demanda de comércio portuário. O Porto do Mucuripe, também conhecido como Porto de Fortaleza, entrou em operação em 1953. Esse porto funciona como instalação pública, possuindo Conselho de Autoridade Portuária (CAP) e OGMO. Atualmente, o Porto do Mucuripe possui infraestrutura para a movimentação de diferentes tipos de mercadorias e cerca de 1.500 pessoas trabalham no porto (COMPANHIA DOCAS DO CEARÁ, 2011).

No TUP do Pecém, a logística e organização do trabalho diferem radicalmente das encontradas no Porto do Mucuripe. No Pecém, as prestadoras negociam contratos diretamente com os armadores ou embarcadores. São responsáveis pela contratação da mão de obra de estivadores e portuários, bem como demais trabalhadores, e tratam das questões de segurança e fornecimento de Equipamento de Proteção Individual (EPI), bem como das boas condições dos equipamentos utilizados. Essa responsabilidade é compartilhada com a Cearaportos, empresa governamental estadual responsável pela administração do porto, que possui um Setor de Segurança do Trabalho. Atuam na estivagem e desestivagem junto aos navios no Terminal do Pecém duas prestadoras, aqui denominadas empresas A e B. A empresa A possuía, na época do estudo, 200 funcionários (60 na estivagem e desestivagem de navios). A empresa B possuía 45 trabalhadores atuando junto aos navios ${ }^{4}$.

Dado o processo de mudanças econômicas e legais que atingiram os portos a partir das décadas de 1980 e 1990, os sindicatos e federações de trabalhadores portuários vêm se preocupando com o aumento de acidentes de trabalho e doenças ocupacionais. A relevância das transformações ocorridas nesse contexto suscitou a necessidade de conhecer e avaliar a situação dos portos no Estado do Ceará. Assim, este estudo objetivou comparar os dois portos localizados no Estado do Ceará no que se refere a avaliar as condições de trabalho e a dinâmica laboral no exercício de operações específicas, comuns ao Porto do Mucuripe e ao Terminal Portuário do Pecém, assim como os riscos à saúde dos trabalhadores envolvidos nas atividades operacionais.

\section{Percurso metodológico}

A pesquisa em questão foi desenvolvida a partir de um trabalho de campo tendo como base a análise da dinâmica laboral. Nesse tipo de análise, utilizando-se das técnicas propostas pela teoria fundamentada (CHARMAZ, 2009), as etapas da pesquisa vão se desenvolvendo paulatinamente, aliando-se a coleta de dados à sua análise, em um processo construtivo de insights e hipóteses sobre o fenômeno em estudo. Assim, a investigação empírica de um determinado fenômeno é realizada a partir de várias técnicas tais como observações, entrevistas, pesquisa documental, entre outras. O objetivo é, a partir dos dados colhidos e baseando-se neles, criar um modelo explicativo sobre um problema da vida real, contextualizado (HENWOOD; PIDGEON, 2007). No caso da análise da dinâmica laboral, o foco é sobre uma determinada situação de trabalho, esteja ela presente em uma única instituição ou organização de trabalho ou em várias organizações, desde que o trabalho seja semelhante. O método é essencialmente qualitativo e interpretativo. Dessa forma, a análise da dinâmica laboral compreende uma série de técnicas de obtenção de dados e sua interpretação em um todo coerente que permita a compreensão do trabalho realizado por um ou vários indivíduos em situações reais de trabalho. A partir dessa compreensão ou modelo, busca-se apontar aspectos do trabalho que podem ser prejudiciais à saúde dos trabalhadores. Assim, o estudo, realizado em 2010 e 2011, envolveu várias técnicas de obtenção de dados, como observações das situações de trabalho, filmagens dos trabalhadores em atividade, com o acompanhamento da narrativa dos trabalhadores, denominada, por nós, de análise dialógica, além da realização de entrevistas com os vários atores envolvidos na organização e determinação das condições de trabalho.

O início da investigação deu-se a partir do contato com as autoridades responsáveis pelos dois portos, para obtenção das autorizações visando a realização da pesquisa. Em seguida foram efetuadas visitas iniciais aos locais e entrevistas abertas, não estruturas, com gestores, médicos do trabalho e engenheiros de segurança. Foram também entrevistados quatro representantes dos sindicatos ligados ao Porto do Mucuripe: dos estivadores, dos arrumadores, dos conferentes e dos portuários. Essas entrevistas foram transcritas na íntegra e analisadas de acordo com o esquema da análise de

\footnotetext{
4 Comunicação pessoal do presidente do Sindicato dos Empregados Terrestres em Transportes Aquaviários, Operadores Portuários e Entidades Afins do Estado do Ceará (SETTAPORT-CE).
} 
conteúdo temática do discurso proposto pela Teoria Fundamentada. Tendo em vista o objetivo proposto, realizaram-se, também, observações e filmagens das atividades de desembarque de contêineres e de carvão, sendo as filmagens acompanhadas do diálogo com os trabalhadores ou capatazes.

É importante salientar que o método utilizado difere substancialmente daquele normalmente utilizado nas observações ergonômicas tradicionais, tendo em vista as especificidades do trabalho portuário e a diversidade de tarefas realizadas pelos trabalhadores. Assim, não é possível observar a mesma operação várias vezes, pois mudam o navio e a carga a cada visita realizada. O método utilizado aqui se aproxima do proposto por Clancey (2006) para observações de trabalho em situação natural. A meta foi observar o ciclo completo de cada um dos processos, registrando-se sistematicamente todas as atividades exercidas pelos portuários a cada operação, a fim de conhecer o trabalho real feito por eles e identificar a organização e as condições laborais que podem colocá-los em risco. Na medida do possível, durante a execução das operações, os trabalhadores eram indagados sobre as atividades que estavam sendo realizadas (análise dialógica). Pelo fato de se tratarem de atividades não repetitivas, a utilização de protocolos seria um fator limitante nas análises. Assim, optou-se por realizarem-se as filmagens de forma livre e, posteriormente, remontarem-se os ciclos completos das atividades, com o auxílio das explicações fornecidas pelos próprios trabalhadores.

No total, foram realizadas dez visitas em cada uma das instalações estudadas, com duração média de quatro horas e com aproximadamente uma hora e meia de filmagem cada, obtendo-se cerca de 30 horas de registro. Essas filmagens foram editadas retirando-se os trechos com atividades repetidas ou pouco ilustrativas. Os diálogos foram transcritos e utilizados na descrição das atividades. Apenas no Pecém foram filmadas atividades noturnas e essas filmagens foram realizadas pelo representante sindical do SETTAPORT. As filmagens editadas de cada operação foram apresentadas aos trabalhadores, em grupos focais, objetivando-se a confrontação e o esclarecimento de aspectos específicos do trabalho.

Os documentos obtidos foram então analisados com o auxílio do programa Atlas TI (versão 6.2), separando-se as operações de acordo com sua continuidade e submetendo-se as observações e discursos a uma análise de conteúdo, como proposto por Charmaz (2009) na sua descrição da Teoria Fundamentada. Esse procedimento possibilitou uma descrição detalhada do trabalho em cada uma das operações, independentemente do trabalhador que a estava realizando.
O projeto como um todo foi aprovado pelo Comitê de Ética em Pesquisa da Universidade de Fortaleza, sob o parecer n. 159/2010, e todos os participantes da pesquisa assinaram o Termo de Consentimento Livre e Esclarecido, conforme os preceitos das normas éticas de pesquisa. Além disso, foi garantido aos participantes o anonimato e a possibilidade da retirada de seu consentimento a qualquer tempo.

\section{Resultados}

\section{A chamada para o trabalho e a organização do trabalho}

O Porto do Mucuripe utiliza o sistema de TPA (Trabalhadores Portuários Avulsos), associado às contratações feitas pelos operadores portuários com a intermediação do OGMO. O Mucuripe possuía, na época da pesquisa, 251 TPAs registrados no OGMO e esses trabalhadores estavam ligados a sindicatos específicos: estivadores, portuários, conferentes, vigias e arrumadores. O OGMO é o responsável pela segurança e demais relações trabalhistas.

A chamada dos trabalhadores no Porto do Mucuripe para a realização de atividades a serem desenvolvidas tanto nos navios quanto nos cais, pátios e armazéns é feita em um pavilhão ao lado do edifício do OGMO. O pavilhão é composto de duas grandes salas com bancos de madeira: uma específica para os estivadores, indicando a importância da categoria e marcando a separação das atividades terra/navio, e a outra para os demais trabalhadores. Somente os estivadores podem trabalhar dentro do navio; as outras atividades, realizadas nos cais, pátios ou armazéns, são feitas pelas "categorias de terra". Nas duas salas há um compartimento separado por uma janela de vidro, onde ficam os técnicos que fazem o controle de frequência/presença dos trabalhadores. Numa das paredes de cada um dos dois salóes ficam os quadros com a programação de navios e o controle do número dos trabalhadores.

As chamadas ocorrem três vezes por dia, às 6 horas da manhã, às 11 h e às 17 h, mas a realização das chamadas depende da disponibilidade de trabalho naquele período (o porto funciona ininterruptamente, inclusive nos finais de semana). Quando não há programação suficiente para os três horários, uma das chamadas pode não ocorrer. As chamadas convocam os TPAs para trabalhar nos períodos das 7 às $13 \mathrm{~h}$, das 13 às 19 h e das 19 à 1 h. Às vezes, dependendo da programação dos navios, há chamadas extras. Quando uma chamada extra é programada, os sindicatos são avisados por telefone, para que convoquem seus trabalhadores. 
Os portuários são chamados a partir de seu número individual, distribuído pelos sindicatos, sendo esse procedimento previsto pela Convenção Coletiva anual. Cada sindicato possui sua própria sequência. Há também uma sequência separada para a capatazia ${ }^{5}$ de cada uma das categorias de trabalhadores. De acordo com as necessidades dos navios que entram ou saem do porto e da decisão dos operadores portuários, são definidos os ternos ${ }^{6}$ de cada categoria para o trabalho em um determinado navio, pátio ou armazém.

Os trabalhadores se apresentam para a chamada, fazendo constar sua presença por meio da "passagem do seu cartão" no relógio de ponto, o que deve ser feito antes do início da chamada. Se o trabalhador chamado estiver presente no pavilhão, ele é alocado para o terno de trabalho e fica aguardando para entrar no porto. Se o trabalhador correspondente ao número chamado não estiver presente, passa-se para o número seguinte e assim por diante. A capatazia é alocada por rodízio entre os trabalhadores, de forma que todos possam passar por ela. São chamados à parte os operadores de maquinários (guindastes, por exemplo), de acordo com sua especialidade e treinamento.

Formados os ternos, os trabalhadores entram no porto e são instruídos sobre as tarefas que devem realizar. Terminado o serviço, eles devem esperar a próxima oportunidade de trabalho, desde que ocorra um período de descanso de pelo menos 11 horas entre um turno e outro.

Os ganhos dos TPAs dependem do serviço realizado e do tipo de carga manipulada. Em função disso, na chamada, já sabedores do tipo de navio, da carga e do serviço a ser realizado, os trabalhadores escolhem se apresentar ou não para o trabalho. É claro que isso significa "certa sabedoria" sobre como burlar a chamada para se colocar presente quando "a carga é boa”. A carga é boa quando a equação quantidade de trabalho/ganho é favorável ao trabalhador.

De acordo com os técnicos entrevistados, há dois tipos de TPAs: os registrados no OGMO que, na época da pesquisa, somavam 251 trabalhadores no total (contando todas as categorias), e os cadastrados, que constituem uma reserva, trabalhadores disponíveis mas que não fazem parte da equipe permanente do OGMO, embora possam estar ligados aos diversos sindicatos. Na eventualidade de não se apresentarem portuários registrados em número suficiente para o serviço, os cadastrados são chamados.

Já o Terminal Portuário do Pecém, que foi construído dentro dos parâmetros estabelecidos pela Lei de Modernização dos Portos, possui Prestadoras de Serviços Operacionais. No Pecém não há CAP nem OGMO.
As empresas se utilizam de mão de obra própria, em geral terceirizada, e os contratos de trabalho são por tempo indeterminado (MEDEIROS, 2005).

As prestadoras são responsáveis pela definição dos ternos de acordo com suas programações e pelas demais definições quanto ao trabalho de estiva e capatazia, embora seja voz corrente no Terminal do Pecém de que lá "não há estivadores, apenas trabalhadores". Há uma diferença marcante na forma de contratação do trabalho entre as duas empresas que operam na estivagem e desestivagem no Terminal. A empresa A paga um salário fixo aos seus estivadores e a B mantém um sistema de pagamento similar ao existente no Mucuripe, isto é, os trabalhadores recebem de acordo com a carga estivada.

As chamadas para o trabalho no Terminal do Pecém são realizadas fora do ambiente do porto, nas respectivas prestadoras. De acordo com a programação dos navios, os ternos são formados e apresentam-se no ambiente do porto para o trabalho.

\section{Operação com contêineres}

Uma das principais tarefas dos estivadores, quando do carregamento ou descarregamento de um navio de contêineres, são as tarefas de peação e despeação. A tarefa compreende soltar ou amarrar com hastes de metal os contêineres, uns aos outros e a pontos específicos do chão do porão do navio, para evitar seu deslocamento durante a viagem.

O terno para essa atividade é composto de seis estivadores que trabalham em dupla, tanto no Mucuripe quanto no Pecém. Na despeação, as roscas que prendem as hastes de amarração são desatarrachadas até o destravamento, em seguida, são retiradas, ou deslocadas para baixo, no caso daquelas que se ancoram no chão do porão. A operação contrária, de amarração, é chamada de peação. Cada contêiner é preso por pelo menos duas hastes em forma de cruz na sua lateral. Além das hastes, na confluência entre os contêineres há uma cruzeta, denominada "castanha" ou locker. As castanhas se atrelam automaticamente (por meio do peso do contêiner), mas devem ser destravadas para que o contêiner se solte dos demais e possa ser retirado.

Em alguns momentos, as hastes e/ou castanhas, devido ao movimento do navio, intempéries ou outras eventualidades, não se soltam com facilidade e o trabalhador deve, então, aplicar esforços físicos para tentar soltá-las. Para realizar essa tarefa, utilizam-se instrumentos e chaves, o que exige força e destreza por

\footnotetext{
5 Os capatazes são responsáveis pela coordenação e supervisão das operações.

6 Ternos são equipes de trabalho definidas para a execução de uma tarefa específica em um turno de trabalho.
} 
parte do trabalhador e pode provocar acidentes, tais como cortes, lacerações e até quedas. Essa atividade requer estratégias operatórias diferenciadas para sua realização, uma delas é o trabalho cooperativo da dupla: um dos trabalhadores segura a haste enquanto o outro a destrava. O esforço físico é evidente e pode estar associado aos dados encontrados na pesquisa de Cavalcanti et al. (2005), no qual um grande número de trabalhadores do Mucuripe apresentava diagnóstico de problemas osteoarticulares.

Uma vez solto o contêiner das amarras, o guindaste entra em ação. No caso das operações observadas, os guindastes utilizados eram das operadoras portuárias, guindastes de terra, que se deslocam sobre o cais. A pega do guindaste (denominada spreader) se ajusta ao tipo de contêiner que está sendo manipulado. Durante essa operação, os estivadores, no convés, através de sinais com braços, mãos e gritos, guiam o guindasteiro para posicionar a pega exatamente sobre o contêiner. Uma vez posicionada, a pega se acopla ao contêiner e inicia-se o seu deslocamento para terra. No cais, os portuários realizam o trabalho de sinalizar para o guindasteiro o posicionamento do contêiner sobre o caminhão, que já deve estar próximo ao navio. Nessa operação, antes do posicionamento sobre o veículo, os dois portuários retiram as castanhas, ficando quase abaixo do contêiner, jogando-as no cais. As castanhas, depois de posicionado o contêiner, são recolhidas. Posicionado o contêiner na prancha, o caminhão o leva para o pátio e a operação recomeça com o próximo contêiner a ser retirado. Dependendo do navio e do ritmo do trabalho, o tráfego de caminhões no cais é intenso, podendo provocar atropelamentos.

No caso da colocação de contêineres, esse é retirado do caminhão pelo guindaste e o estivador, que se localiza no porão ou convés do navio, sinaliza para o guindasteiro para posicioná-lo na pilha correta. Em seguida inicia-se o trabalho de peação.

As sinalizações são bastante precárias, feitas apenas com os braços e mãos e, em muitos casos, os trabalhadores utilizam o capacete para sinalizar ao guindasteiro. Isso é considerado normal, apesar de colocar o trabalhador em situação de risco.

As superfícies onde o trabalhador fica posicionado para realizar a (des)peação, localizadas no porão e convés do navio, são pequenas e bastante instáveis. O trabalhador pode ter de passar de uma pilha de contêineres para outra, em posições mais baixas ou mais altas, "escalando" a lateral de um contêiner ou pulando de alturas, às vezes, de dois ou mais contêineres empilhados. No caso da despeação de porão, as superfícies onde o trabalhador se localiza são mais estáveis, entretanto hastes de amarração e outros materiais que nelas se acumulam dificultam o trabalho.
Os riscos que essas operações envolvem são evidentes, pois enquanto os trabalhadores realizam a sua atividade, os guindastes estão transportando os contêineres acima deles (Figura 1). Assim, há sempre o risco de um contêiner cair ou escorregar e atingir o trabalhador, tanto no porão do navio quanto no cais. A mesma situação pode ocorrer com as castanhas. Ao comentar sobre acidentes ocorridos nessas operações, os trabalhadores reconhecem o risco, mas o minimizam e naturalizam a situação, possivelmente como uma estratégia de defesa (DEJOURS, 1991).

Digna de nota é a operação, extremamente insegura, de destravamento de castanhas dos últimos contêineres das pilhas do convés. Para realizar essa tarefa, o trabalhador é alçado e se posiciona na parte de cima do último contêiner, a grande altura. Lá em cima, com a haste de destravamento, tenta alcançar a castanha para destravá-la. Com o balanço do navio e os ventos, há uma maior probabilidade de risco de queda (Figura 2). Vários acidentes fatais desse tipo foram relatados pelos trabalhadores.

A observação das atividades no Terminal Portuário do Pecém foi feita a certa distância, uma vez que, no que se refere a visitantes, as regras de segurança do Terminal são bem mais estritas do que as existentes no Mucuripe.



Figura 1 Colocação de contêiner no caminhão

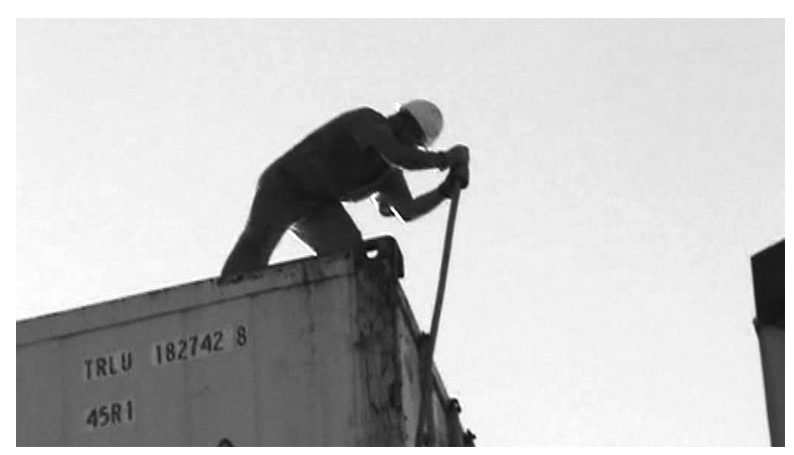

Figura 2 Despeação de contêineres: destravando o locker do último contêiner da pilha 
A atividade de retirada e colocação de contêineres no terminal do Pecém é bastante similar à realizada no Porto do Mucuripe: as definições das operações são idênticas, uma vez que o processo envolve o mesmo tipo de maquinário. No entanto, observou-se que a atividade ocorre de forma bem mais rápida, com um intenso ir e vir de caminhões que esperam em fila para receber e efetuar a retirada dos contêineres. O terminal do Pecém é um porto offshore, o cais fica a uma distância maior do pátio e armazéns e os caminhões trafegam, às vezes em alta velocidade, pela ponte entre o cais e os pátios.

Em uma das ocasiões, observou-se o conserto do spreader do guindaste da prestadora, que tinha sofrido uma avaria. $\mathrm{O}$ serviço foi realizado no próprio cais, com o guindaste utilizando outro spreader para a movimentação dos contêineres, deslocados acima dos trabalhadores.

Em uma das filmagens noturnas no Pecém observou-se a operação de contêineres com utilização de spreader manual, uma vez que o automático estava avariado. Nesse caso, os estivadores permaneciam em cima dos contêineres, engatando o spreader manualmente. Verificou-se também que, para ganhar tempo, os estivadores permaneciam sobre o spreader enquanto ele estava sendo içado para outro contêiner, operação bastante insegura, uma vez que o balanço do navio ou qualquer descuido do guindasteiro pode levar a um acidente grave de queda. Acompanhou-se também a operação com um contêiner open top, com a utilização de uma escada para se subir e descer do equipamento, uma vez que, nesse caso, não há superfície de apoio na parte superior.

O que se pôde observar, por meio das filmagens e entrevistas, é que o trabalho de peação e despeação de contêineres é cansativo e perigoso, exigindo esforço físico, uma vez que as hastes de amarração apresentam ferrugem e desgaste, e estratégias de cooperação por parte dos trabalhadores, como a despeação aos pares.

O trabalho de destravamento dos contêineres também se torna bastante perigoso quando se trata do destravamento de lockers dos contêineres superiores, ficando os trabalhadores expostos a quedas de grande altura. Na confrontação dos trabalhadores com a filmagem dessas operações foram relatados vários acidentes fatais.

O portuário, que trabalha no cais (terra), também fica exposto a riscos, na medida em que a atividade exige rapidez e destreza na retirada das castanhas (desembarque de contêineres), devendo o trabalhador ficar o menor tempo possível debaixo do contêiner que está sendo retirado do navio.

Embora o Terminal do Pecém seja considerado mais moderno que o Porto do Mucuripe, pela gestão portuária, o processo de trabalho permanece o mesmo no que se refere à tecnologia empregada. Com relação às condições de trabalho, no entanto, dada a configuração do terminal e as diferenças no tipo de contratação, observou-se um ritmo de trabalho mais elevado nas operações com contêineres.

\section{Desembarque de carvão a granel}

Na operação de desembarque de carvão no Porto do Mucuripe, o carvão a granel chega acomodado nos porões de um navio especial que possui um guindaste com um grab (espécie de colher mecânica que se abre para recolher o material). A operação consiste em dirigir o grab para o porão, por meio de sinais. Os estivadores (em número de três na nossa observação) ficam no porão do navio guiando a operação. O guindasteiro abre o grab que vai escavando o carvão, fecha a colher quando cheia e a dirige para o coletor de carvão (moega) já posicionado no cais, próximo ao navio. Nessa operação, o estivador procura se colocar fora do caminho do grab, sinalizando ao guindasteiro para onde dirigir o equipamento.

No cais, o grab é aberto sobre a moega, fazendo o carvão escoar para a caçamba do caminhão que se localiza abaixo dela. Junto à moega se posiciona um portuário em uma plataforma. Seu trabalho consiste na operação do dispositivo de abertura e fechamento da moega. A visualização nessa operação é difícil e, enquanto abre e fecha a moega, o trabalhador se curva e torce o tronco para poder enxergar a descida do carvão. A tarefa consiste também em avisar ao motorista do caminhão quando ele deve avançar ou retroceder, de forma a distribuir o carvão por igual dentro da caçamba. Quando a caçamba está cheia, o portuário avisa, por meio de um sinal sonoro, que o caminhão já pode partir. Quando quase todo o carvão foi retirado, o porão é varrido e o restante de carvão (rechego) vai sendo empilhado para ser recolhido, o mesmo ocorre com o rechego no cais.

No pátio, a caçamba é virada, formando pilhas de carvão que depois será transportado por um trem de carga. A operação de colocação do carvão no trem de carga utiliza um aspirador e um duto.

Toda a operação com carvão gera bastante sujeira, com derramamento do material sobre o cais e nos arredores do pátio, no caso do Mucuripe. Dessa forma é necessário que a equipe de arrumadores e portuários faça uma limpeza contínua, varrendo o cais e o pátio. O principal problema com essa operação é a presença de partículas no ar, decorrentes da manipulação do material. É importante ressaltar que os trabalhadores não usam nenhum tipo de proteção ao realizar essa atividade. 
No caso do terminal do Pecém, o processo dessa atividade difere do observado no Mucuripe, uma vez que um carregador automático lá opera. Nesse caso, o carvão é aspirado e passa pelo duto condutor diretamente para uma esteira e, dessa, para o caminhão. A operação produz menos resíduos do que a observada no Mucuripe. No entanto, quando chega ao pátio, a operação é igual, sendo o carvão empilhado para ser posteriormente aspirado, geralmente em vagões de trem, gerando igualmente resíduos que podem ser aspirados pelos trabalhadores.

Nota-se que a atividade de desembarque de carvão difere substancialmente nos dois portos dada a presença de equipamento automático no Pecém. A operação no Mucuripe pode causar problemas no sistema musculoesquelético do portuário que opera a moega em vista das posições de trabalho desfavoráveis que deve assumir para realizar a atividade.

\section{Operações exclusivas do Porto do Mucuripe}

Algumas das operações observadas ocorreram apenas no Porto do Mucuripe, entre elas desembarque de trilhos e de sacas de cimento. São operações com cargas consideradas não nobres, uma vez que seu acondicionamento não é padronizado, como no caso dos contêineres, que exigem um maior número de trabalhadores ou operações mais complexas no seu manuseio. Talvez por essas razões essas cargas não sejam desembarcadas no Terminal do Pecém.

A atividade de desembarque de trilhos é bastante complexa e perigosa. Os trilhos chegam acomodados, ao longo dos porões, arrumados paralelamente uns aos outros, com tacos de madeira separando cada camada. Para essa atividade, o spreader do guindaste consiste em duas "cadeirinhas" com vários encaixes. Esses devem se acoplados aos trilhos para que possam ser içados. Uma parte do terno de seis estivadores fica dentro do porão, por cima dos trilhos, aguardando a descida do spreader que é guiado para uma determinada posição. $\mathrm{O}$ engate é feito automaticamente mas, às vezes, ou os trilhos não estão na posição correta ou o spreader não abre corretamente e os operadores devem então forçar o engate. Durante a descida do equipamento, esse pode atingir o trabalhador. Assim, a operação exige força e destreza e os estivadores trabalham em duplas, com um estivador protegendo o outro de um possível "golpe" da cadeira. Feito o engate, os estivadores se afastam para locais do porão protegidos do alcance do lote de trilhos que está sendo içado. A retirada do lote próximo à parede do porão torna a atividade mais perigosa, pois o equipamento pode prensar o trabalhador junto à parede. Os separadores de madeira são içados junto com o lote e seguem soltos em cima dos trilhos durante o içamento, podendo cair sobre os trabalhadores no cais ou no porão.
Os trilhos são içados lentamente, pois seu comprimento não permite um bom equilíbrio e qualquer movimento do navio é suficiente para provocar um deslocamento do lote por sobre as pessoas no convés ou porão do navio. Para que os trilhos se mantenham na posição correta durante o processo de içamento para o cais, há duas cordas presas às cadeiras que os portuários, do cais, vão puxando à medida que o lote vai sendo içado. As cordas servem também para posicionar os trilhos sobre o cais de forma paralela ao navio para que possam ser posteriormente recolhidos por empilhadeiras e colocados na caçamba dos caminhões. O tráfego de empilhadeiras e caminhões nessa operação é bastante intenso. Trata-se, portanto, de uma operação bastante perigosa e cansativa. As estratégias dos trabalhadores, tanto no porão quanto no cais, exigem coordenação das equipes para evitar golpes do maquinário e para direcionar o spreader e trilhos para o posicionamento correto.

A tarefa de retirada de sacos de cimento consiste na passagem de cintas (operação denominada de cintagem) pelos bags (conjunto de 22 sacos de cimento de $50 \mathrm{~kg}$ cada um), para que o spreader de ganchos possa iça-los. A tarefa exige um trabalho contínuo dos estivadores, que andam sobre os sacos no porão do navio, separando os que serão içados e passando a cinta por eles. Quando o spreader é baixado, os estivadores acoplam as cintas aos ganchos e se afastam para evitar possíveis golpes da carga: durante o levantamento corre-se o risco de a carga balançar e atingir o trabalhador.

De acordo com os estivadores, o trabalho requer esforços físicos na cintagem dos bags. Outro ponto ressaltado é que a retirada dos sacos posicionados no centro do porão é mais fácil do que os que se encontram próximos à parede. Assim, os ternos iniciais vão retirando os bags posicionados no centro do porão, para ganhar tempo e receber uma maior porcentagem em produtividade. No entanto, esse comportamento prejudica os ternos posteriores, pois os sacos junto às paredes formam colunas que podem desabar e atingir os trabalhadores (Figura 3).

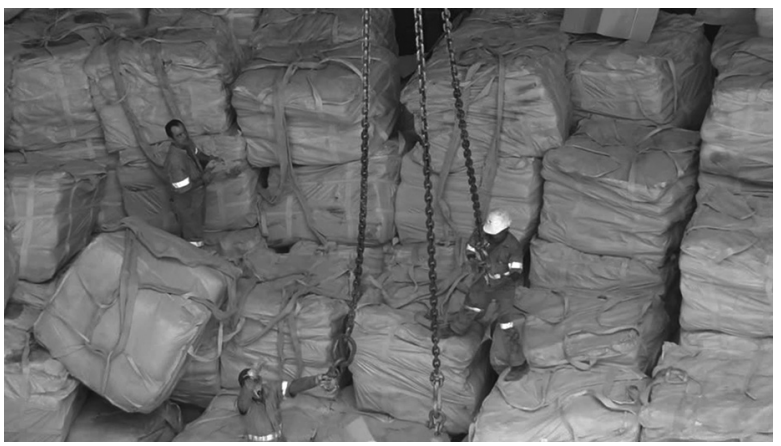

Figura 3 Cintagem de bags de cimento 
No cais, os portuários dirigem, por meio de sinais para o guindasteiro, os bags içados para a prancha de um caminhão já posicionado no cais. Os portuários sobem na prancha e desengatam as cintas. Quando a prancha está cheia, sinalizam para o caminhoneiro seguir para o pátio. Esse trabalho pode ocasionar queda de sacos no cais ou queda dos trabalhadores.

No pátio, os portuários realizam a atividade inversa. Nesse trabalho são utilizadas empilhadeiras com quatro ganchos. As cintas dos bags são engatadas aos ganchos da empilhadeira, com os portuários sobre a prancha do caminhão. Após essa operação, os bags são retirados e empilhados no pátio ou armazém para posterior retirada.

A operação como um todo leva a avarias nos sacos de cimento, liberando a substância. Exatamente por isso, estivadores e portuários devem utilizar máscaras de proteção, o que nem sempre acontece.

\section{Discussão}

A análise da dinâmica laboral mostrou que a organização do trabalho no Porto Mucuripe e no de Pecém apresentam diferenças marcantes quanto à contratação da mão de obra e distribuição do trabalho, diferenças essas originadas e dirigidas pela nova legislação. No Porto do Mucuripe, os estivadores são TPAs, que prestam serviço ao OGMO, sem vínculo empregatício. Por esse motivo, há alguma autonomia na escolha do dia e turno em que desejam trabalhar e, também, é possível optar, até certo ponto, sobre a carga que querem operar, bem como com a equipe com que querem trabalhar, como foi observado na chamada dos trabalhadores. Os estivadores preferem o que chamam de carga boa, ou seja, aquela que permite obter maior produtividade e, com isso, maior ganho. Essa estratégia funciona como mecanismo de mobilização contra a precarização do trabalho (MENDES, 2007). No entanto, segundo informações dos representantes sindicais, os trabalhadores do Mucuripe tiveram perdas na remuneração e na disponibilidade de trabalho, bem como no poder de sua representatividade na negociação dos ganhos do trabalho.

Há que se destacar que os estivadores registrados no OGMO são, em sua maioria, trabalhadores que já exerciam funções portuárias antes da nova legislação e que, portanto, aprenderam o ofício no contexto de relações familiares e de amizade, que era o processo estabelecido, na época, para admissão na função, segundo informações do representante do sindicato dos estivadores. O conhecimento tácito passado de pai para filho, a sabedoria adquirida na atividade compartilhada, bem como o orgulho pelo exercício do ofício são aspectos ainda bastante presentes entre esses trabalhadores e que influenciam o seu fazer, assim como proporcionam vivências positivas, como comentado pelos representantes sindicais entrevistados.

Por outro lado, os trabalhadores do Pecém encontram-se em situação de insegurança quanto ao emprego e, dependendo da prestadora, com baixos salários. A maioria dos trabalhadores da empresa A são contratados pela CLT (Consolidação das Leis do Trabalho), mas também recebem de acordo com a carga estivada. Esses, em geral, eram TPAs no Porto do Mucuripe e passaram a exercer suas funções no Terminal do Pecém. Segundo informações dos trabalhadores, no entanto, o trabalho no Terminal é mais desgastante, pois é realizado em um ritmo mais acelerado, como mostraram as observações.

Ainda segundo os trabalhadores, os estivadores da empresa B são os que se encontram em pior situação empregatícia. Contratados pela CLT, seus ganhos não dependem da quantidade e qualidade da carga estivada, recebendo um salário fixo ao final do mês. Além disso, os trabalhadores dessa empresa são jovens e com nenhuma ou pouca experiência no manuseio de cargas. Esse contexto pode levar ao que foi observado por Fabiano et al. (2010) no Porto de Gênova: um aumento no risco de acidentes devido à inexperiência do pessoal contratado.

Os resultados mostraram que, nos dois portos, há tentativa de implantar um novo enquadre organizativo que, à primeira vista, pelo menos no Porto do Mucuripe, parece respeitar a autonomia dos TPAs, característica histórica desses trabalhadores. No entanto, as mudanças implantadas com a Lei de Modernização dos Portos apontam para um maior controle da mão de obra nesse porto, em comparação com a situação anterior à nova legislação. Já no Terminal do Pecém não há autonomia na escolha dos trabalhos, uma vez que não há intermediação sindical alguma na contratação e determinação do preço dos serviços, como no Mucuripe. O maior controle sobre os trabalhadores leva a uma intensificação e aumento da carga de trabalho que, por sua vez, podem acarretar um aumento no número de acidentes.

Das atividades observadas, nota-se que as mais desgastantes e perigosas são as realizadas com contêineres. Essas operações podem provocar queda de altura, queda de materiais e exigem esforço e destreza por parte dos trabalhadores. A tarefa de destravamento de castanhas dos últimos contêineres pode provocar quedas de grandes alturas, causando acidentes fatais. Para essas operações seria importante a utilização de cintos de segurança e outros equipamentos de proteção que não estavam sendo utilizados durante as observações realizadas. Em outros portos, como no Porto de Hamburgo, por exemplo, os portuários executam as operações de destravamento dos últimos contêineres das pilhas de dentro de um elevador operado 
pelo guindaste e com o uso de cinto de segurança (KAISER, 2007). A segurança nessas operações e a utilização de EPIs são previstas pela NR29, porém foram observadas condições extremamente inseguras, sem nenhuma proteção, nos dois portos.

Com relação ao Pecém, as operações noturnas com contêineres se mostraram ainda mais perigosas, com os trabalhadores se colocando em risco de queda devido à necessidade de realizar o trabalho o mais rápido possível, com equipamentos nem sempre em boas condições de uso. No geral, embora no Pecém as normas de segurança quanto à visitação, entrada no cais e em equipamentos sejam mais restritivas, as operações acontecem em um ritmo mais acelerado e com grande tráfego de caminhões. Esse ritmo mais rápido, em condições técnicas similares, pode levar a um maior número de acidentes.

As operações com carvão são realizadas de forma diferenciada nos dois portos, pois o Pecém utiliza carregadores automáticos, enquanto no Mucuripe o trabalho é manual. Comparadas com as operações com contêineres, essas operações são menos perigosas nos dois portos, no entanto expõem os trabalhadores a partículas no ar e podem ocasionar doenças ocupacionais.

Embora constatados os avanços tecnológicos, em especial, no Porto do Pecém, em algumas tarefas que exigem comunicação entre os trabalhadores como, por exemplo, a indicação do posicionamento correto dos contêineres no caminhão, a sinalização é efetuada por meio de um sistema de sinais realizados com o capacete e braços, mostrando a precariedade das condições de trabalho nos dois portos. Em algumas das operações que exigiam comunicação observou-se o uso do rádio, mas nem sempre esse equipamento estava disponível, restando aos trabalhadores a comunicação por meio dos sinais.
Observou-se também que, com a construção do Terminal do Pecém, as cargas consideradas não nobres, cujo manuseio é mais difícil em vista de seu acondicionamento, são realizadas apenas no Mucuripe, e as operações mais nobres, e provavelmente mais rentáveis, passaram a ser feitas no Pecém. Segundo informações dos gerentes dos dois portos, isso diminui a disponibilidade de trabalho no Mucuripe, levando a perdas de remuneração para seus trabalhadores.

Segundo os representantes sindicais entrevistados, as inovações tecnológicas e a reestruturação produtiva podem ter reduzido alguns riscos, como pode ser observado nas atividades mais automatizadas realizadas, principalmente, no Porto do Pecém, mas possibilitaram a intensificação do ritmo de trabalho, trazendo novos riscos ocupacionais, como é o caso da intensa movimentação de contêineres.

\section{Conclusão}

Embora o trabalho de embarque e desembarque de mercadorias nos dois portos seja reconhecidamente perigoso, é descrito como simples, uma vez que se trata de uma atividade que não exige muitos procedimentos e tampouco requer alta escolaridade. No entanto, o que se observou é que, dada a natureza variada da tarefa e suas especificidades, a realidade do trabalho é bem mais complexa e exige destreza e conhecimento do trabalhador, principalmente porque variáveis do ambiente: condições climáticas, condições dos equipamentos e dos navios, entre outras, dificultam o trabalho e o tornam, até certo ponto, imprevisível. $\mathrm{O}$ fato de a atividade ser realizada em equipes menores, que pouco se conhecem, e com um limite de tempo, torna essas dificuldades ainda mais relevantes e pode colocar em risco a saúde e a vida dos trabalhadores.

\section{Contribuições de autoria}

Maciel, R. H.: coordenadora do projeto, participou do planejamento da pesquisa, coleta de dados e análise, bem como da elaboração do texto e aprovação de sua versão final. Gonçalves, R. C.; Matos, T. G. R.; Fontenelle, M. F.: participaram do planejamento da pesquisa, coleta de dados e análise, bem como da elaboração do texto e aprovação de sua versão final. Santos, J. B. F.: participou do planejamento da pesquisa, fez contribuições importantes na sua revisão crítica e aprovou a versão final do texto.

\section{Referências}

AGUIAR, M. A. F; JUNQUEIRA, L. A. P.; FREDDO, A. C. D. M. O Sindicato dos Estivadores do Porto de Santos e o processo de modernização portuária. Revista de Administração Pública, Rio de Janeiro, v. 40, n. 6, p. 997-1017, 2006.

ARAÚJO, S. M. Da precarização do trabalhador portuário avulso à uma teoria da precariedade do trabalho. Revista Sociedade e Estado, Brasília, v. 28, n. 3, p. 565-586, 2013. http://dx.doi.org/10.1590/S010269922013000300006.

BOURGUIGNON, D. R.; BORGES, L. H. A reestruturação produtiva nos portos e suas implicações sobre acidentes de trabalho em 
estivadores do Espírito Santo. Cadernos de Saúde Coletiva, Rio de Janeiro, v. 14, n. 1, p. 63-80, 2006.

BRASIL. Lei no 8.630, de 25 de fevereiro de 1993. Dispõe sobre o regime jurídico da exploração dos portos organizados e das instituições portuárias e dá outras providências. Diário Oficial da União, Brasília, DF, 26 dez. 1993. p. 2351.

. Ministério do Trabalho e Emprego. Portaria

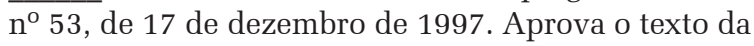
Norma Regulamentadora NR-29, relativa à segurança e saúde no trabalho portuário. Diário Oficial da União, Brasília, DF, 29 dez. 1997.

. Lei $\mathrm{n}^{\mathrm{0}}$ 12.815, de 5 de junho de 2013. Dispõe sobre a exploração direta e indireta pela União de portos e instalações portuárias e sobre as atividades desempenhadas pelos operadores portuários. Diário Oficial da União, Brasília, DF, 5 jun. 2013a. Seção 1, Edição Extra, p. 1.

. Decreto $\mathrm{n}^{\circ}$ 8.033. Regulamenta o disposto na Lei $\mathrm{n}^{\mathrm{O}} 12.815$, de 5 de junho de 2013, e as demais disposições legais que regulam a exploração de portos organizados e de instalações portuárias. Diário Oficial da União, Brasília, DF, 28 jun. 2013b. Seção 1, p. 4.

BROOKS, M. R. The governance structure of ports. Review of Network Economics, Berlin, v. 3, n. 2, p. 168183, 2004. http://dx.doi.org/10.2202/1446-9022.1049.

CARRION, V. Comentários à Consolidação das Leis do Trabalho: legislação complementar e jurisprudência. 28. ed. São Paulo: Saraiva, 2003.

CAVALCANTI, F. F. G. et al. Estudo sobre os riscos da profissão de estivador do Porto do Mucuripe em Fortaleza. Ciência \& Saúde Coletiva, Rio de Janeiro, v. 10, p. 101-110, 2005. Suplemento. http://dx.doi. org/10.1590/S1413-81232005000500013.

CHARMAZ, K. A construção da teoria fundamentada. Porto Alegre: Artmed, 2009.

CLANCEY, W. J. Observation of work practices in natural settings. In: ERICSSON, A. et al. (Ed.). Cambridge handbook on expertise and expert performance. New York: Cambridge University Press, 2006. http://dx.doi.org/10.1017/ CBO9780511816796.008.

COMPANHIA DOCAS DO CEARÁ. O Porto do Mucuripe. Fortaleza. Disponível em: <http://www.docasdoceara. com.br/o-porto>. Acesso em: 20 nov. 2011.

DEJOURS, C. A loucura do trabalho: estudo de psicopatologia do trabalho. São Paulo: Cortez-Oboré, 1991.

FABIANO, B. et al. Safety and the container revolution: a statistical study on human factor and occupational accidents over the long period. Safety Science, Amsterdam, v. 48, n. 8, p. 980-990, 2010. http://dx.doi.org/10.1016/j.ssci.2009.08.007.
GOMES, J. C.; JUNQUEIRA, L. A. P. Cultura e transformação do trabalho no porto de Santos. Revista de Administração Pública, Rio de Janeiro, v. 42, n. 6, p. 1095-1119, 2008.

GOULARTI FILHO, A. Melhoramentos, reaparelhamentos e modernização dos portos brasileiros: a longa e constante esper. Economia e Sociedade, Campinas, v. 16, n. 3, p. 455-489, 2007. http://dx.doi.org/10.1590/S0104-06182007000300007.

HENWOOD, K.; PIDGEON, N. Grouded theory in psychology research. In: CAMIC, P. M.; RHODES, J. E.; YARDLEY, L. (Ed.). Qualitative research in psychology: expanding perspectives in methodology and design. Washington: APA, 2007. p. 131-156.

KAISER, R. Der Hamburg hafen. [S.l.]: [s.n.], 2007. Vídeo. Disponível em: < https://www.youtube.com/ watch? $\mathrm{v}=\mathrm{cN} 8 \mathrm{SibU293U}>$. Acesso em: 13 out. 2015.

LACAZ, F. A. C. O campo saúde do trabalhador: resgatando conhecimentos e práticas sobre as relações trabalho-saúde. Cadernos de Saúde Pública, Rio de Janeiro, v. 23, n. 4, p. 757-766, 2007. http:// dx.doi.org/10.1590/S0102-311X2007000400003. PMid:17435873.

LU, C. S.; SHANG, K. C. An empirical investigation of safety climate in container terminal operators. Journal of Safety Research, Chicago, v. 36, n. 3, p. 297-308, 2005. http://dx.doi.org/10.1016/j.jsr.2005.05.002. PMid:16024045.

MACHIN, R.; COUTO, M. T.; ROSSI, C. C. S. Representações de trabalhadores portuários de Santos, SP sobre a relação trabalho-saúde. Saúde e Sociedade, São Paulo, v. 18, n. 4, p. 639-651, 2009. http://dx.doi. org/10.1590/S0104-12902009000400008.

MAGIOLI, F. S. O trabalhador portuário avulso. [S.l.]: WebArtigos Direito, 2008. Disponível em: <http:// www.webartigos.com>. Acesso em: 20 out. 2010.

MARCHETTI, D. S.; PASTORI, A. Dimensionamento do potencial de investimentos para o setor portuário. BNDES Setorial, Rio de Janeiro, v. 24, n. 10, p. 3-33, 2006.

MEDEIROS, A. D. Fatores intervenientes na competitividade dos portos brasileiros: um estudo de caso no nordeste. 2005. 153 f. Dissertação (Mestrado em Engenharia de Produção)-Universidade Federal do Rio Grande do Norte, Natal, 2005.

MENDES, A. M. Psicodinâmica do trabalho: teoria, método e pesquisas. São Paulo: Casa do Psicólogo, 2007.

MONIÉ, F.; VIDAL, S. M. D. S. C. Cidades, portos e cidades portuárias na era da integração produtiva. Revista de Administração Pública, Rio de Janeiro, v. 40, n. 6, p. 975-995, 2006. http://dx.doi.org/10.1590/ S0034-76122006000600003. 
NASCIMENTO, H. A. S. O nascimento de um novo trabalhador portuário: reestruturação produtiva e corporativismo: um estudo sociológico acerca da resistência dos portuários capixabas ao processo de modernização dos portos. 1999. 222 f. Dissertação (Mestrado em Sociologia)-Universidade Estadual de Campinas, Campinas, 1999.

PÉREZ, N. J. La política pública de privatización del sector portuario y su impacto en la organización del trabajo en el puerto de Buenaventura. Pensamiento y Gestión, Colombia, v. 25, p. 178-213, 2008.

PORTO, M. F. S. Análise de riscos nos locais de trabalho: conhecer para transformar. São Paulo: INST, 2000.

SAUNDRY, R.; TURNBULL, P. Contractual (in)security, labour regulation and competitive performance in the port transport industry: a contextualized comparison of Britain and Spain. British Journal of Industrial Relations, London, v. 37, n. 2, p. 271-294, 1999. http:// dx.doi.org/10.1111/1467-8543.00127.

SOARES, J. F. S. et al. Percepção dos trabalhadores avulsos sobre os riscos ocupacionais no porto do Rio Grande, Rio Grande do Sul, Brasil. Cadernos de Saúde Pública, Rio de Janeiro, v. 24, n. 6, p. 1251-1259, 2008.
http://dx.doi.org/10.1590/S0102-311X2008000600006. PMid:18545751.

SOARES, J. F. S.; CEZAR-VAZ, M. R.; SANT'ANNA, C. F. Prevenção de agravos e promoção de saúde: um estudo com trabalhadores portuários. Texto Contexto: Enfermagem, Florianópolis, v. 20, n. 3, p. 225-234, 2011. http://dx.doi.org/10.1590/S010407072011000300002 .

TARA. In: MICHAELIS Moderno Dicionário da Língua Portuguesa. [S.l.]: Melhoramentos, 2009. Disponível em: <http://michaelis.uol.com.br/ moderno/portugues/index.php?lingua $=$ portuguesportugues\&palavra $=$ tara $>$. Acesso em: 13 out. 2015.

TONGZON, J.; HENG, W. Port privatization, efficiency and competitiveness: some empirical evidence from container ports (terminals). Transportation Research Part A, Policy and Practice, Oxford, v. 39, n. 5, p. 405424, 2005. http://dx.doi.org/10.1016/j.tra.2005.02.001.

TORRES, L. F. R. Um estudo analítico da supervia eletrônica de dados: um modelo de gestão eletrônica para os portos brasileiros. 2008. 167 f. Dissertação (Mestrado)-Escola Politécnica, Universidade de São Paulo, São Paulo, 2008. 